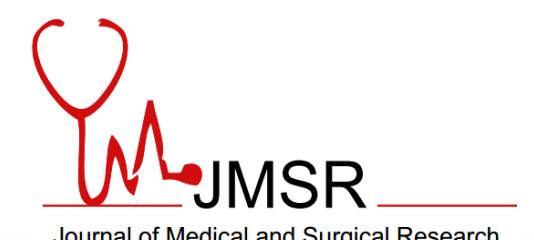

\title{
MEDIASTINUM LYMPH NODE HYDATIDOSIS.
}

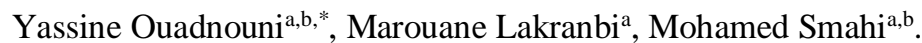 \\ ${ }^{a}$ Department of Thoracic Surgery, University Hospital Hassan ${ }^{\text {Idd }}$, Fez, Morocco \\ ${ }^{\mathrm{b}}$ Faculty of Medicine and Pharmacy, Sidi Mohamed Benabdellah University-Fez, Morocco
}

\section{Corresponding Author:}

Y. Ouadnouni,

Address: Department of Thoracic Surgery, University Hospital Hassan ${ }^{\text {IId }}$, Fez, Morocco

E-mail: ouadnouni2@yahoo.fr

Copyright (C) 2012- 2014 Y. Ouadnouni and al. This is an open access article published under Creative Commons Attribution-Non Commercial- no Derives 4.0 International Public License (CC BY-NC-ND). This license allows others to download the articles and share them with others as long as they credit you, but they can't change them in any way or use them commercially.

DOI: $10.46327 / \mathrm{msrjg} .1 .000000000000009$

DOI url: https://doi.org/10.46327/msrjg.1.000000000000009

A 55 year old woman, presented to our hospital with a one year history of coughing and left chest pain. A chest CT-scan showed mediastinal, pleural and pulmonary cystic lesions evoking hydatidosis. Surgical exploration found a cystic lesion of the aorta-pulmonary window.

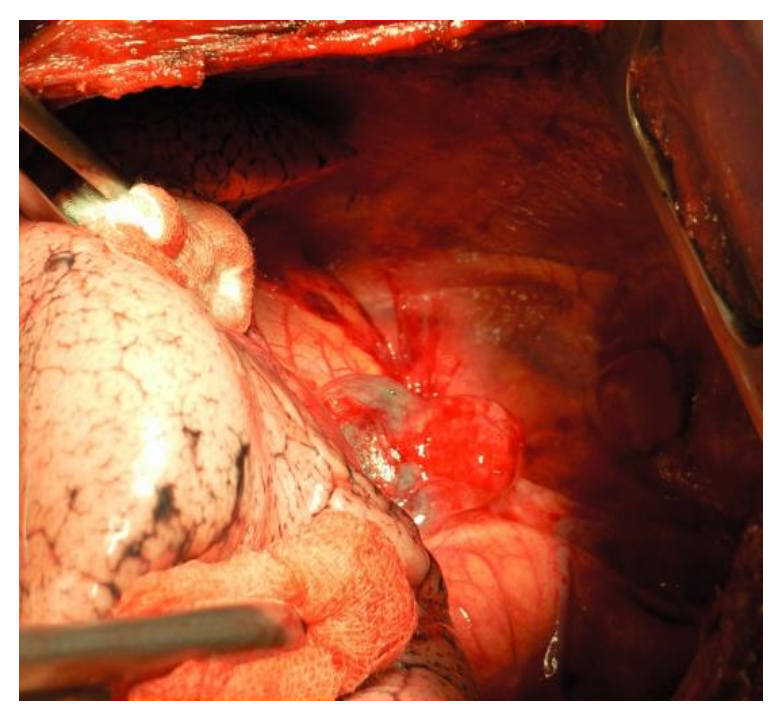

Figure 1: Peroperative view showing a cystic lesion of the aorta-pulmonary window
This is a hydatid cyst of a mediastinum lymph node. No similar case report is found in literature.

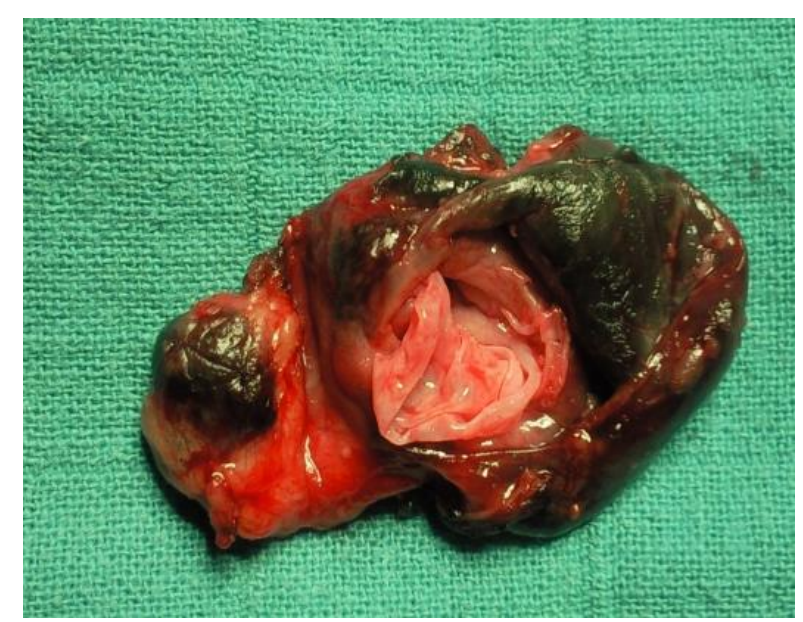

Figure 2: hydatid cyst of lymph node

Keywords: Hydatidosis; Mediastinum; Lymph node; Surgery.

CONFLICT OF INTEREST : The authors had no conflict of interest to declare.

\section{REFERENCES:}

1 Buttenschoen K, Kern P, Reuter S, Barth TF.Hepatic infestation of Echinococcus multilocularis with extension to regional lymph nodes.Langenbecks Arch Surg. 2009;394(4):699-704.

2 Damak T, Triki A, Chargui R, Laamouri B, Chemlali M, Bouzaiene $\mathrm{H}$ et al.Hydatid cyst mimicking an axillary lymph node. Tunis Med. 2012;90(11):836-7 